\title{
A Method for Studying Acidification and Eutrophication Potentials of a Residential Neighbourhood
}

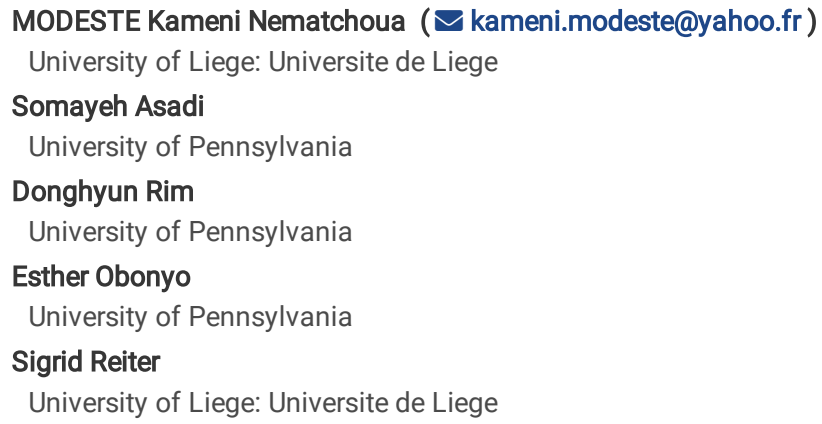

Research

Keywords: Acidification, Eutrophication, Neighborhood, Countries, environmental impacts

Posted Date: August 10th, 2021

DOI: https://doi.org/10.21203/rs.3.rs-746429/v1

License: (c) (7) This work is licensed under a Creative Commons Attribution 4.0 International License. Read Full License 


\section{Abstract}

Acidification and Eutrophication are two environmental impacts that have a significant effect on air pollution and human health. The quantitative analysis of these two impacts remains hitherto unknown at the scale of new neighborhoods. The main purpose of this research is to evaluate, analysis and compare the acidification and eutrophication potentials of one neighborhood initially located in Belgium. To perform this comparison, the same neighborhood design is applied to in 150 countries, but four parameters are adapted to each country: energy mix, local climate, building materials, and occupants' mobility. In addition, this research evaluates the induced environmental costs of the neighborhood over 100 years and examines the impact of the photovoltaic panel on these environmental impacts. This research, extended to the scale of several nations, will enable new researchers, and especially policy-makers, to measure the effectiveness of sustainable neighborhoods. Eutrophication and acidification potentials were assessed under different phases (construction, use, renovation, and demolition), with Pleiades ACV software. Among the four local parameters (energy mix, local materials, climate, and transport, the energy mix has the most significant effect on the two studied environmental impacts. The results show that $72 \%$, and $65 \%$ of acidification, and eutrophication potentials are produced during the operational phase of the neighborhood. In the case of sustainable neighborhoods, the acidification potential is $22.1 \%$ higher in the 10 top Low incomes countries than the 10 top High-income countries. At the neighborhood scale the main eutrophication potential component is water (34.2\%), while, the main source of acidification potential is electricity production $(45.1 \%)$

\section{Introduction}

In recent years, large-scale growth of the pollution rate in the world has been noticed. This has led many researchers to focus on finding solutions to reduce environmental pollution ${ }^{1}$.These solutions, which are the result of differences between different political systems, wider problems such as diffuse pollution, loss of biodiversity, acidification, and eutrophication have caused huge losses to humanity ${ }^{1}$.

Generally, there are no products whose environmental impact is zero. Environmental impacts primarily affect air quality, water quality, resources and human health ${ }^{1}$. The protection of ecosystems is a requirement that will be imposed on building designers. The emissions coming from building sector, transportation and industry, affect the environment. One of the fundamental steps in environmental assessment is determining the nature, intensity, extent, and duration of all pollution impacts attributed to buildings, ${ }^{1-2}$. All different impacts, such as greenhouse gas, acidification, biodiversity, and eutrophication, have not the same damage to the environment. Indeed, some of them are more harmful and destructive than others. Globally, at the beginning of the twenty-first century, a leap is made in the international awareness of environmental problems. Eutrophication is an imbalance caused by increasing the concentrations of nitrogen and phosphorus in a medium that leads to excessive growth of plants and algae due to the high availability of nutrients ${ }^{2}$.The algae arising from the effect of eutrophication absorbs large amounts of oxygen when they die and decompose. Their proliferation causes the death of the aquatic ecosystem present ${ }^{3}$.The eutrophication sources are multiple and can give rise to complex interaction situations depending on the various factors (phosphorus, nitrates, temperature,

morphological functioning of the media, flow, etc.). The eutrophication degree describes the trophic (agronomic or ecological) status of a terrestrial or aquatic environment or an agro-environment where living things are exposed to "excess", ${ }^{4}$.Biodiversity of eutrophication-depleted environments is losing its richness, impacting non-aquatic wildlife and humans ${ }^{4}$.

Acidification is defined as emissions which increase acidity concentration (lower pH) of water and soils. Acidification is the result of atmospheric pollution resulting from nitrogen, sulphur and anthropogenic origin, in the form of nitrogen oxides $\left(\mathrm{NO}_{\mathrm{x}}\right)$ or ammonia ${ }^{4}$.Acidification is one of important contemporary environmental hazards at the global scale that directly affects the ecosystem, ${ }^{5}$. Acid rain is essentially composed of sulfur dioxide $\left(\mathrm{SO}_{2}\right)$ and $\left(\mathrm{NO}_{\mathrm{x}}\right)$ that can lead to the death of some species. But, also, these types of rain cause major damages to buildings ${ }^{5}$. The higher the value of acidification potential (PA), more the environmental damages are important. Bouwman and Vuuren ${ }^{6}$ explained that today, the load of acidification, and eutrophication reached 6-15\% and 7$18 \%$ of the total area of natural ecosystem.Several studies such as Heijung et al. ${ }^{7}$ showed that the acidification potential varies with atmospheric environments and also regional characteristics. Seppälä at al. ${ }^{8}$ suggested one of the main indicators in life cycle analysis applications for studying a sitedependent on acidification and terrestrial eutrophication.

Wei-Jun Cai et al. ${ }^{9}$ showed water eutrophication originated from the water acidification and development of hypoxia In 2013 , a study of life cycle assessment carried out by Environmental Protection Agency(EPA) in single family homes reported the acidification potential(AP) of $5500 \mathrm{kgS02}$ eq and eutrophication potential (EP) of $320 \mathrm{kgPo} 4 \mathrm{Eq} .1^{0}$. Other studies in the same field campaign were detailed $\mathrm{in}^{11-15}$. Please describe the research gap here. Where are the areas that need more research? What information is needed? Why are you pursuing this study?

The main objective of this study is to assess, analyse, and compare acidification(AP) and eutrophication potentials(EP) of a sustainable-neighbourhood initially located in Belgium as well as the same neighbourhood model has been later designed in 150 countries which varies with climates, energy mix, use of materials and mobility behaviours. Thus, our study focuses on a whole neighbourhood and is not limited to the case of one country, instead, it examines 150 countries, with very different climates and energy mix. The quantification and analysis of AP and EP related to the implementation of photovoltaic panels on the neighbourhood roofs take into account all the climatic zones of the world through150 countries. Note that this work did not focus on a single life cycle stage (for example, renovation or use) like some previous studies, but we evaluated all the different phases.

\section{Methodology}

We carried out the environmental study of a sustainable neighborhood located in Belgium (Europe) over 100 years, and then, we adopted the same neighborhood design in 149 other countries, while keeping four parameters specific to each country: energy mix, local climate, building materials, and occupants' mobility. In addition, we calculated the costs related to two environmental impacts: acidification and eutrophication. Finally, we changed some building materials to evaluate their impacts on the eutrophication and acidification costs. 
Overall, this research is constituted of five important steps (1) choice and neighbourhood design;

(2) LCA of the selected neighbourhood in Belgium; (3) modelling the same neighbourhood in 149 other countries with adaptation of the four local parameters and life cycle assessment; (4) study of the cost of (AP and EP); and (5) applying one scenario for mitigating some environmental impacts.

The following sections ( 2.1 to 2.6) describe neighborhood case study, the countries, and databases for this research, the analysis of data and the environmental indicators, the simulation of LCA for each country, the method of calculating the environmental cost, and the neighbourhood improvement scenario tested.

\subsection{Initial analysis of the eco-neighbourhood}

This neighborhood is initially located in the Liege city in Belgium, and the same design is adapted in 149 countries represented in the world. The full description of this sustainable neighbourhood is found in ${ }^{38}$.

In this research, only the residential section of the neighbourhood was studied. The residential eco-neighbourhood consists of $35000 \mathrm{~m}^{2}$ comprising $10000 \mathrm{~m}^{2}$ of roads, residence around 219 inhabitants, studied on a period of 100 years $^{16-17}$.

\subsection{Design of the same eco-neighbourhood in other countries}

The same eco-neighborhood is built in capitals located in other 149 countries. The choice of the capital, for representing each country was not random; indeed, in the most of these countries, the capital was considered as the most populated region of the country, with the highest environmental pollution and energy consumption. Theelpopulation density has a significant influence on all the environmental impacts.

We simultaneously applied four parameters for adapting this neighbourhood in each country:the energy mix of each country, the local climate of each country, typical building materials used in each country and occupants' mobility.

The International Energy Agency (IEA) database ${ }^{18}$ and the Energy Information System of each country were used to gather the information on the energy mix and electricity mix. Using the Pleiades-ACV software, it was possible to freely select the different energy sources (in \%), such as nuclear, fuel, coal, gas and renewable energy; then, assigning their corresponding values.

The information on the local climate of each country was evaluated with the most recent version of Meteonorm (7.3.1) which contains around of 8,325 weather stations ${ }^{19}$

The information on the construction materials was evaluated on the basis of 2018-2020 standard thermal regulation of each country, but also from information issue to the

UN-habitat as well as based on literature reviews (for some African and Asian countries, without recent building standards). Regarding inhabitant mobility, the data was based on a different rate of occupants commuting daily: $80 \%$ in developed countries (USA, Japan, Germany, France, UK, etc.) and 50\% in developing countries (Cameroon, Madagascar, Haiti, Thailand, etc.). The distanceof the weekly commute between home and trade is $1 \mathrm{~km}$; distance from the public transport network is $500 \mathrm{~m}$, distance from the daily commute to work is on average between $5 \mathrm{~km}$ and $10 \mathrm{~km}$. Presence of bike path and public transportation such as bus, subway, and tram.

\subsection{Environmental data}

The data used in this study is based on the ECOINVENT (version 2.2, 2012). Some details were showed in ${ }^{20}$. The ECOINVENT Centre is known as one of leaders in environmental sustainability data ${ }^{21}$.

In this study, we assessed two (02) environmental impacts of the studied neighborhood:

Acidification (PA); eutrophication (PE) ${ }^{22-24}$.

These different environmental indicators are presented in Table1.

Table1. Average LCA results of the eco-neighbourhood (in Liege city) in terms of calculated impacts

\begin{tabular}{|llcl|}
\hline Environmental Indicator(CEN) & Unit & Yearly value & Value(per $\mathrm{m}^{2} /$ year $)$ \\
\hline Acidification & $\mathrm{Kg} \mathrm{SO} 2 \mathrm{eq}$. & 860.92 & 0.09 \\
Eutrophication & & & \\
\hline
\end{tabular}

\subsection{LCA Simulation software}

In this study, we used a combination of all the new IZUBA energy software.Indeed, the interface of the most recent version (Pleiades-ACV software, version 4.19.1.0)is divided into 6 modules: Library, Modeller(called ALCYONE for the old software version), BIM, Editor(called COMFIE-PLEIADES),Results, and ACV

Page $3 / 13$ 
(nova-EQUER). Modeler, ALCYONE software, has as main role to draw the building , solar masks, the zoning... ${ }^{25}$.

We used the software essentially made up of five components: Generals (Construction Data, Project Library, LCA Association, Weather and Horizon); Plan; 3D; Calculation. Some physical characteristics of the studied neighbourhood are shown in table2.

Table 2. Wall Composition

\begin{tabular}{|c|c|c|c|c|c|}
\hline element & component & $\mathrm{E}(\mathrm{cm})$ & $\rho^{\star} e\left(k g / m^{2}\right)$ & $\lambda(w / m . k)$ & $\mathrm{R}\left(\mathrm{m}^{2} \cdot \mathrm{K} / \mathrm{W}\right)$ \\
\hline \multirow{4}{*}{ Coated exterior wall } & exterior coating & 1.5 & 26.0 & 1.150 & 0.01 \\
\hline & Expanded polystyrene & 32.0 & 8.0 & 0.032 & 10.0 \\
\hline & Limestone silico block & 15.0 & 270.0 & 0.136 & 1.10 \\
\hline & ceiling & 1.3 & 11.0 & 0.325 & 0.04 \\
\hline \multirow{5}{*}{ Barded outer wall } & Cement fiber cladding & 2.0 & 36.0 & 0.950 & 0.02 \\
\hline & Air blade & 1.2 & 0.0 & 0.080 & 0.15 \\
\hline & polyurethane & 24.0 & 7.0 & 0.025 & 9.60 \\
\hline & Limestone silico block & 15.0 & 27.0 & 0.136 & 1.10 \\
\hline & ceiling & 1.3 & 11.0 & 0.325 & 0.04 \\
\hline \multirow{4}{*}{ High floor } & PDM sealing & - & - & - & - \\
\hline & Polyurethane & 40.0 & 12 & 0.025 & 16.00 \\
\hline & Concrete slab & 25.0 & 325 & 1.389 & 0.18 \\
\hline & Ceiling & 1.3 & 11 & 0.325 & 0.04 \\
\hline \multirow{5}{*}{ Intermediate floor } & Chappe + coating & 8.0 & 144 & 0.700 & 0.11 \\
\hline & polyurethane & 1.0 & 0 & 0.030 & 0.33 \\
\hline & Aerated concrete & 8.0 & 48 & 0.210 & 0.38 \\
\hline & Concrete slab & 25.0 & 325 & 1.389 & 0.18 \\
\hline & Ceiling & 1.3 & 11 & 0.325 & 0.04 \\
\hline \multirow[t]{3}{*}{ Low floor } & Chappe + coating & 8.0 & 144 & 0.700 & 0.11 \\
\hline & polyurethane & 25.0 & 8 & 0.025 & 10.00 \\
\hline & Concrete slab & 25.0 & 575 & 1.750 & 0.14 \\
\hline \multirow[t]{5}{*}{ Internal wall } & Ceiling & 1.3 & 11 & 0.325 & 0.04 \\
\hline & Limestone silico block & 15.0 & 270 & 0.136 & 1.1 \\
\hline & Expanded polystyrene & 4.0 & 1 & 0.032 & 1.25 \\
\hline & Limestone silico block & 15.0 & 270 & 0.136 & 1.10 \\
\hline & ceiling & 1.3 & 11 & 0.325 & 0.04 \\
\hline
\end{tabular}

Editor, COMFIE-PLEIADES software is designed for making the thermel simulation of buildings ${ }^{25-26}$. This neighbourhood was regrouped in 10 blocks with heating requirements shown in Table 3.

Table 3. Heating requirements of different neighbourhood buildings in the basic and high configuration of a floor. 


\begin{tabular}{|lll|}
\hline & \multicolumn{2}{c|}{ Heating requirements $\left(\mathrm{kWh} / \mathrm{m}^{2}\right.$.year $)$} \\
\hline Buildings & Initial situation & First floor \\
\hline A3 & 15 & 14 \\
B2 & 12 & 12 \\
\hline B3 & 14 & 13 \\
\hline D1 & 19 & 20 \\
\hline D2 & 20 & 20 \\
\hline D3 & 20 & 21 \\
\hline D4 & 18 & 19 \\
\hline C1 & 12 & 11 \\
\hline C2 & 13 & 12 \\
\hline C3 & 13 & 11 \\
\hline Mean & 15.6 & 15.3 \\
\hline
\end{tabular}

ACV module,nova-EQUER, is required to assessment the different environmental impacts ${ }^{26}$. This module is essentially made up of four datasets as follows:

(i) Building/neighborhood data

The original data come from the Pleiades, this thermal/ACV coupling allows to automatically recover all the characteristics of the building: data on the structure of the building and the elements involved in thermal calculations and/or energy consumption. These data are then supplemented with specific LCA data: all elements that are not part of the thermal study; general and administrative data concerning the current operation and the building or neighbourhood; specific or adjusted seizures for energy, water, waste, and transport.

(ii) Software organization

The Pleiades ACV interface is structured around five axes:

a. Library: Environmental Impact Data Libraries, General Calculation Characteristics. In this research, we fixed: surplus of materials at the site $5 \%$, default typical service life of families of element: interior and exterior doors 30 years, global equipment 20 years, glazing 30 years, coating 10 years; distance of transport: site of production towards building site $100 \mathrm{~km}$, site towards inert discharge finally of life: $20 \mathrm{~km}$.

b. Project: Project management with structure data for any type of project and use of the building with the EQUER engine. In this research, we fixed: Loss of electrical network from $9 \%$ to $40 \%$ according to country. Water system yield: $80 \%$, hot water consumption $40 \mathrm{~L} /$ day/person; cold water consumption 100L/day/person; Selective collection of glass: yes; sorted glass: $90 \%$; incinerated waste $40 \%$; recovery to incineration: yes; substituted energy: gas or fuel oil (depending on the country); recovery yield: $80 \%$; selective collection of paper: yes; sorted paper: $80 \%$; lane between the site and the garbage dump: $20 \mathrm{~km}$; distance from the site to the incinerator: $10 \mathrm{~km}$; distance from the site to the recycling center: $100 \mathrm{~km}$.

c. Experimentation: Specific seizures PEBN E+C-;

d. Calculation and results: Start the calculations and consult the results.

e. Neighbourhood: neighbourhood Management.

The acidification potential of soils and water is evaluated by the potential of $\mathrm{H}+\mathrm{ion}$. It is also sometimes evaluated by the ability to release an equivalent amount of $\mathrm{SO}_{2}$. The indicator is calculated as follows:

$$
\text { Acidificatoin }=\sum_{i}^{\square} P A_{i} \times m_{i}
$$

With $\mathrm{m}_{\mathrm{i}}$ : mass of (i) element emitted in $\mathrm{kg}$. The eutrophication potential is:

$$
\text { Eutrophication }=\sum_{i}^{\text {II }} P E_{i} \times m_{i}
$$

With mi: quantity of substance i released into the air, water or soil in $\mathrm{kg}$. The indicator is therefore expressed in $\mathrm{kg}$ of equivalents (PO4) ${ }^{2-}$

\subsection{Environmental cost}

The acidification and eutrophication quantities were translated into environmental costs, which make them comparable to each other. The cost calculation is based on the method Monetization of the (Global method monetize) ${ }^{27-29}$. The tables below show the conversion values of the environmental impacts of environmental costs.

Table4 .Monetary indicators for CEN indicators ${ }^{30}$. 


\begin{tabular}{|llll|}
\hline Environmental Indicator(CEN) & Unit & Belgium( $€$ /unit ) & Rest of World( $€$ /unit \\
\hline Acidification & $\mathrm{kg} \mathrm{SO} 2 \mathrm{eq}$. & 1.01 & 0.17 \\
\hline Eutrophication & $\mathrm{kg}(\mathrm{PO} 4)^{3-}$ eq & 40.00 & 8 \\
\hline
\end{tabular}

Table5.The average environmental cost of each phase of the eco-neighbourhood in Belgium.

\begin{tabular}{|c|c|c|c|c|c|c|c|}
\hline Environmental impacts & Year & $€ /$ unit & Construction & Operation & Maintenance & Dismantling & Total cost \\
\hline \multirow[t]{6}{*}{ Acidification } & \multirow[t]{3}{*}{2030} & $€ /$ dwelling & 448.2 & 607.1 & 66.3 & 8.8 & 1130.4 \\
\hline & & $€ / \mathrm{m}^{2}$ & 0.5 & 0.5 & 0.1 & 0 & 1.2 \\
\hline & & $€ /$ inhabitant & 20.4 & 27.6 & 3.1 & 0.4 & 51.4 \\
\hline & \multirow[t]{3}{*}{2050} & $€ /$ dwelling & 1137.8 & 1540.9 & 168.4 & 22.4 & 1620.5 \\
\hline & & $€ / \mathrm{m}^{2}$ & 1.4 & 1.7 & 0.4 & 0 & 3.2 \\
\hline & & $€ /$ inhabitant & 51.7 & 65.5 & & 7.6 & 130.4 \\
\hline \multirow[t]{6}{*}{ Eutrophication } & \multirow[t]{3}{*}{2030} & $€ /$ dwelling & 8850.9 & 15272.4 & 1089.9 & 69.7 & 25282.9 \\
\hline & & $€ / \mathrm{m}^{2}$ & 10.4 & 15.6 & 0 & 0 & 26.0 \\
\hline & & $€ /$ inhabitant & 402.5 & 694.2 & 49.5 & 3.2 & 1149.2 \\
\hline & \multirow[t]{3}{*}{2050} & $€ /$ dwelling & 22467.7 & 38768.4 & 2766.7 & 176.9 & 64179.7 \\
\hline & & $€ / \mathrm{m}^{2}$ & 26.4 & 39.6 & 0 & 0 & 66.0 \\
\hline & & $€ /$ inhabitant & 1021.3 & 1762.2 & 125.8 & 8.1 & 2917.3 \\
\hline
\end{tabular}

\subsection{Mitigation of impacts}

We also examined a scenario to reduce both environmentals costs. The sustainable strategy involved using photovoltaic panels combined with mobility.

In the reference scenario, the total electricity was supplied from the central electricity grid of each country. In this new configuration, we have a photovoltaic system on all the roofs on the site.Installed photovoltaic panels cover a total area of $580 \mathrm{~m}^{2}$ that can yield a peak power of $82.8 \mathrm{~kW}$. The residential buildings use energy only for light and HVAC systems. The installation will consist of monocrystalline photovoltaic solar panels. They will be oriented toward the south in the northern hemisphere and toward the north in the southern hemisphere; they will also be inclined at $37^{\circ}$ for the countries located in the temperate and cold zones and inclined at $45^{\circ}$ for the countries located in the hot zone. This allows us to have optimal inclination in all the countries. We have thenperformed the thermal simulation of each building and completed the final LCA of the neighbourhood.

We have also examined the impact of mobility on the neighborhood's environmental record. In our basic scenario, we considered an important use of the car for daily commuting. We recapitulated the mobility hypotheses: (i) Initial scenario: $80 \%$ of the occupants commute daily in developed countries and $50 \%$ of the occupants commute daily in developing countries; the distance from home to work of 5-10 km is carried out daily by car; the distance from home to shops of 1 $\mathrm{km}$ is done weekly by car. (ii) new scenario or "Urban Site" scenario: $100 \%$ of the occupants make the trip daily in all the countries; the distance from home to work of $2-5 \mathrm{~km}$ is done daily by bus; the distance from home to shops of $0.5-1 \mathrm{~km}$ is carried out weekly by bike or on foot. Finally, both scenarios have been combined to obtain a mixed scenario having a significant effect on the three environmental impacts assessment.

\section{Results}

This section presents and analyses two environmental impacts such as Acidification (AP) and Eutrophication (EP) as well as their associated costs. The parameters that most influence the different environmental impacts are highlighted.

\subsection{Analysis of environmental impacts in different phases of neighbourhood}

Figures 1 and 2 show the results of the two environmental impacts assessment of studied neighborhood, adapted in several countries over a period of 100 years that include four different phases: (1) construction, (2) operation, (3) renovation, and (4) demolition.Figure 1 shows that in America (Northern and Southern regions), the majority of acidification potential (the $70 \%, \mathrm{AP}$ ) are issued during the operation or use phase of the neighbourhood. During the demolition phase, alone the $0.51 \%$ of AP was emitted. In Europe (Northern and Southern parts), the $77.5 \%$ of (AP) are generated from the operation phase of the neighbourhood, and only $3 \%$ during the renovation of this one. In addition, in Asia (southern and northern regions), and Africa, the $72 \%$ and $70 \%$, of (AP), 
respectively, are generated during the operation phase of building. These results suggest that, globally, in the world, in the sustainable neighbourhood, the "use phase of the neighbourhood" produces between $67 \%$ and $79 \%$ of (AP); and the construction phase from $12 \%$ to $25 \%$ of this one.

In the figure2, it is interesting to notice that, during the neighbourhood demolition phase, the (EP) is null. The $65 \%$ and $14 \%$ of total (EP) is rejected during the phase of use and renovation, in Africa and America, respectively. On the other hand, on average, $20.0 \%$ and $30.5 \%$ are produced during the neighbourhood construction phase in the countries of Europe and Asia.

Globally, the majority of two environmental impacts are produced during "utilization phase of neighborhood", and a minority during "demolition phase of the neighborhood ". These findings confirm results found by Nematchoua et al. ${ }^{36}$ who explained that the majority of environmental impacts are produced during the operational phase of building or neighborhood.

\subsection{Analysis of environmental impacts per square meter living space}

Figure3 and 4 show the analysis of two environmental impacts per square meter living space per year due to a neighbourhood adapted in several regions in the world.

As shown in figure 3 , the average of the acidification of an eco-neighborhood (including buildings, road construction, and daily mobility) located in the 150 studied countries is $0.249 \mathrm{~kg} \mathrm{SO} 2 / \mathrm{m}^{2}$. Indeed, the average acidification is $0.388 \mathrm{~kg} \mathrm{SO} / \mathrm{m}^{2}$ in Africa; $0.347 \mathrm{~kg}$ - SO2/m ${ }^{2}$ in America; and $0.340 \mathrm{~kg}-\mathrm{SO} 2 / \mathrm{m}^{2}$ in European Union. Note that, it is $0.262320 \mathrm{~kg} \mathrm{SO} 2 / \mathrm{m}^{2}$ in the high-income (top 20) countries while $0.320 \mathrm{~kg} \mathrm{SO} 2 / \mathrm{m}^{2}$, in the low-income (top 10 ) countries. These results show that in sustainable buildings or neighborhoods, the acidification potential is more significant in top 10 low-income countries than top 10 highincome countries. In addition, it is worth to note that acidification potential is more important in Africa than (America and Europe). These results are not surprising, they vary according to the environment of adaptation of the eco-neighborhood. Indeed, in low-income countries, mostly located in Africa, South America, poor maintenance of neighborhood infrastructure and poor waste management can be one of the causes.

According to figure 4, the estimated eutrophication potential(EP) values are $0.05 \mathrm{~kg}-\mathrm{P04} / \mathrm{m}^{2}$ in Belgium; $0.08 \mathrm{~kg}-\mathrm{P04} / \mathrm{m}^{2}$ in USA; and0.09kg-P04/m² in (UK, Brazil, Russia, France, Germany, and in Australia).

Globally, the (EP) is of $13.1 \%$ lower in Europe than the average in the 150 countries; on the other hand, the (EP) is $11.5 \%$ lower in the High-income countries (top 20) than the average in the studied countries. It is interesting to see that the EP is $11.0 \%$, and of $10.9 \%$, higher in China, and, Low-income countries, respectively, than the mean in the different studied countries(see figure 4).

\subsection{Analysis of photovoltaic effect on acidification and eutrophication potentials}

The effects of photovoltaic on the acidification and eutrophication were evaluated in this section as shown in the Figures 5 and 6.

Globally, as found in figures (5 and 6), the implementation of the photovoltaic panel (PV) allows reduction of acidification concentration up to $6.3 \%$ at the neighborhood scale. The reduction ratesare $38.6 \%$ in Spain; $15.3 \%$ in Russia; $9.17 \%$ in USA; $22.7 \%$ in China; and $11.7 \%$ in Canada. In the majority of African countries, the implementation of PV increases the acidification potential (see cases of Madagascar island, Ethiopia, Egypt, Nigeria, etc).The results also show that the implementation of the PV produces a high yield of acidification) in the countries with a temperate climate, such as China, France, Belgium, UK, etc.

Globally, reductions of eutrophication potential are up to $10.4 \%$ with the implementation of PV (see figure 6).(EP) decreases to $12.7 \%$ in Germany; $34.3 \%$ in Spain; $32.6 \%$ in Australia; and $8.7 \%$ in Japan.

The global results found, shows that the acidification and eutrophication potential decrease after applying the photovoltaic scenario. In addition, the yield is better in the temperate climate than tropical climate countries.

\subsection{Environmental components and costs}

Figures 7 and 8 show the frequency of the different environmental components in the generation of the acidification and eutrophication, in 29 representative countries located in the five continents of the world (Europe, America, Africa, Asia, and Oceanic).

Globally, the results show that the main source of acidification potential in different countries "electricity production (45.1\%). It is important to note that $22.2 \%$ and $6.9 \%$ of total (AP) emissions come from building material and transportation, respectively. Only $2.8 \%$ of the total acidification is attributed to the heating buildings. However, in Canada and France, more than $20 \%$ of total acidification is due to heating of buildings. According to the figure 8 , the main eutrophication potential source is water (34.2\%). Despite this, $28.9 \%$ and $19.6 \%$ of total (EP) emissions are attributed to building material and electricity. These results reveal that better water management is recommended to reduce the eutrophication potential in urban environments.

Table6 shows some details of acidification and eutrophication costs in some regions.

The global cost of acidification and eutrophication potentials are estimated from $2.4 € / \mathrm{m}^{2}$, and $43.3 € / \mathrm{m}^{2}$, respectively. In China, the eutrophication expenditure cost per square meter is $10.8 \%$ higher than the mean world. In the USA, acidification and eutrophication expenditure costs are $20.8 \%$ and $26.1 \%$, respectively, lower than the mean world. In European Union(27 countries except for the UK), and the Middle East, acidification expenditure costs are $25.0 \%$, and $12.5 \%$, respectively, which are higher than the world mean; while, eutrophication expenditure costs are $13.2 \%$, and $5.8 \%$, respectively, which are lower than the world mean. In Africa, Oceania, and America, the acidification expenditure costs are $37.5 \%, 16.7 \%$, and 20.8\%, respectively, higher than the mean world; while eutrophication expenditure cost is $4.4 \%$ higher in Africa than the mean world, then $7.6 \%$ lower in America than this one. Some details are showed in table 6. 
Table6. Environmental impact cost over 50 years

\begin{tabular}{|lll|}
\hline Region & Acidification $\left(€ / \mathrm{m}^{2}\right)$ & Eutrophication $\left(€ / \mathrm{m}^{2}\right)$ \\
\hline China & 2.3 & 48.0 \\
\hline USA & 1.9 & 32 \\
\hline European Union & 3.0 & 37.6 \\
\hline Middle East & 2.7 & 40.8 \\
\hline Africa & 3.3 & 45.2 \\
\hline Oceania & 2.8 & 40.8 \\
\hline America & 2.9 & 40.0 \\
\hline Low- and middle-income countries & 2.7 & 48.0 \\
\hline High-income countries & 2.2 & 38.3 \\
\hline World & 2.4 & 43.3 \\
\hline
\end{tabular}

Globally, acidification and eutrophication expenditure costs are $22.7 \%$, and $25.3 \%$ higher in Low-income countries than high-income countries. These expenditure costs, although still neglected by public opinion, should be known to the population.

\section{Discussion}

Acidification and eutrophication potentials are two impacts affecting significantly the human health. Nowadays, water eutrophication a major problem for the researchers' the disturbance of the ecosystem[33]. The increase of the air acidity is mainly due to $\mathrm{SO}_{2}, \mathrm{NO}_{\mathrm{x}}$ and $\mathrm{HCl}$ emissions, which, by oxidation, give the acids $\mathrm{HNO} 3$ and $\mathrm{H} 2 \mathrm{SO} 4$. In this research, we have found that $72 \%$ of acidification potential and $65 \%$ and eutrophication potentials are produced during the operational phase of neighbourhood.

These results show that the majority of these two impacts are produced during the operational phase of the neighbourhood. These findings agree with some studies in the literature carried out in a more conventional neighborhood ${ }^{34}$.

Global acidification produces in a sustainable neighbourhood is $0.249 \mathrm{~kg}-\mathrm{SO} 2 / \mathrm{m} 2$. Indeed, this one is $28.2 \%$ higher in Low-income countries than the mean world. In addition, the acidification concentration due to the sustainable neighborhood is $22.1 \%$ higher in Low incomes countries than High-income countries. Despite this, at the world scale, it is important to know that ocean acidification is very significant in some countries such as: US, UK, Germania, France, Chine, Australia, Canada and Japan ${ }^{37}$.Indeed, the pollution rate rejected in nature by the industries located in these countries is very important.

Acidification and eutrophication were showed by Hyoung and Chae ${ }^{35}$, as the main sources of red tide phenomena, forest destruction, and air pollution. A simple case is the acidification of oceans, which refers to the gradual decline in the $\mathrm{pH}$ of the oceans, caused in particular by human pollution. The rate of environmental pollution is becoming more important in low-income countries, with non-mastery of waste treatment techniques. This waste is for the most part thrown into the ocean. The ocean becomes more and more acidic, disrupting the ocean ecosystem in low-income countries. A case study of the Madagascar Island in the Indian Ocean, which these recent decades, the eutrophication rate considerably increased. In the case of the sustainable neighborhood, it is seen that the eutrophication concentration per square meter is $11.6 \%$ lower in High-income countries than the mean world, and $20.2 \%$ lower in High-income countries than Low-income countries.

Several studies focus on the effect of photovoltaic (PV) panels on the reduction of energy consumption in buildings, other studies focus on the carbon content generated by $\mathrm{PV}$, in this research, it is found that the implementation of PV can have a positive effect on other environmental impacts, indeed, it allows to reduce up to $6.3 \%$ of acidification concentration and up to $10.4 \%$ of eutrophication. The analysis of the results of this research showed that the main acidification and eutrophication sources are electricity and water, respectively. The annual expense cost allocated to these two impacts is very important. The eutrophication cost assessed by the square meter in this research is estimated to be up to eighteen times higher than acidification cost. Overall, climate change is very different from ocean acidification. Indeed, climate change is considered as the consequence of a set of greenhouse gases that make the Earth system retain more solar energy (global warming), while, the ocean acidification, is due to increased atmospheric $\mathrm{CO} 2$ levels dissolved in the Ocean.

\section{Declarations}

Conflicts of Interest: The authors declare no conflict of interest.

Availability of data and materials: The data of this study will be available under the require of reader

Funding: No fund for this research

Author Contributions: Conceptualization, M.K.Nand S.R.; methodology,D.R, M.K.N.; software, E.O., S.R.; validation, S.A.,, S.R.; formal analysis, D.R., M.K.N.; investigation, S.A, M.K.N., D.R.; resources, M.K.N., E.O., S.R.; data curation, SA, M.K.N., D.R., S.R.; writing-original draft preparation, E.O, M.K.N., D.R., S.R.; 
writing-review and editing, M.K.N., S.R.; visualization, S.A, M.K.N., D.R., S.R.; supervision M.K.N, S.R.; project administration, D.R, M.K.N., E.O., S.R.;. All authors have read and agreed to the published version of the manuscript.

Acknowledge Not applicable

\section{References}

1. Agence de l'Environnement et de la Maîtrise de l'Énergie(ADEME). https://www.ademe.fr/expertises/consommer-autrement/elements-contexte/impactsenvironnementaux(siteweb visited on July19,2020).

2. Smith, V. H., Tilman, G. D., \& Nekola, J. C. (1999). Eutrophication: impacts of excess nutrient inputs on freshwater, marine, and terrestrial ecosystems [archive]. Environmental pollution, 100(1), 179-196

3. Eutrophisation des milieux aquatiques », Écotoxicologie, janvier 2012http://archive. wikiwix.com/cache/? url=http\%3A\%2F\%2Fwww.ecotoxicologie.fr\%2Feutrophisation.php

4. Heijungs, R., Guinée, J., Huppes, G., Lankreijer, R., Udo de Haes, H., Sleeswijk, A., Ansems, A., Egges, P., van Duin, R., \& de Goede, H. (1992). Environmental Life Cycle Assessment of products. Guide and Backgrounds (CML). Université de Leiden, Leiden.

5. Lena Dahlgren, HåkanStripple, Felipe Oliveira. Life cycle assessment: Comparative study of virgin fibre based packaging products with competing plastic materials.IVL Swedish Environmental Research Institute 2015.1(69)

6. Bouwman AF. Vuuren DP.Global assessment of acidification and eutrophication of natural ecosystems.RIVM(1999), 402001012.

7. 7. Heijungs, R.; Guinée, J.B.; Huppes, G.; Lamkreijer, R.M.; Udo de Haes, H.A.; Wegener Sleeswijk, A.;Ansems, A.M.M.; Eggels, P.G.; van Duin, R.; de Goede, H.P. Environmental Life Cycle Assessment of Products: Guide (Part 1) and Background (Part 2); CML Leiden University: Leiden, The Netherlands, 1992.

8. Seppälä, J., Posch, M., Johansson, M. et al.Country-dependent Characterisation Factors for Acidification and Terrestrial Eutrophication Based on Accumulated Exceedance as an Impact Category Indicator . Int J Life Cycle Assessment (2006) 11: 403. https://doi.org/10.1065/lca2005.06.215.

9. Wei-Jun Cai, Xinping Hu, Wei-Jen Huang, Michael C. Murrell, John C. Lehrter,Steven E. Lohrenz,Wen-Chen Chou,WeidongZhai, James T. Hollibaugh, Yongchen Wang, Pingsan Zhao, XianghuiGuo,Kjell Gundersen, Minhan Dai. Acidification of subsurface coastal waters enhanced by eutrophication. NatureGeosciencevolume4, pages 766-770 (2011).

10. Environmental protection agency(EPA)(2013). Analysis of the life cycle impacts and potential for avoided impactsassociatedwith single-family homes. 530-R-13-004J.

11. Blau, S.;Seneviratne, S. (1995): Acidification and Eutrophication in Life Cycle Assessment. Student thesis. ETH, Zürich, Switzerland

12. Finnveden, G.;Potting, J. (Forthcoming): Eutrophication. Aquatic and terrestrial. State-of-the-art. In: Bare, J.C., Pennington, D.W. and Udo de Haes, H.A. (eds.) International Workshop on Life Cycle Impact Assessment Sophistication. LCA Documents Vol. 7, 2000, ecomed publishers, Germany

13. Potting, J.;Hauschild, M. (Forthcoming): Levels of sophistication in life cycle impact assessment of acidification. Points of discussion additional to the presentation. In: Bare, J.C., Pennington, D.W. and Udo de Haes, H.A. (eds.) International Workshop on Life Cycle Impact Assessment Sophistication. LCA Documents Vol. 7, 2000, ecomed publishers, Germany

14. Udo de Haes, H.A.;Jollier, O.;Finnveden, G.;Hauschild, M.;Krewitt, W.;Mueller-Wenk, R. (1999): Best available practice regarding impact categories and category indicators in Life Cycle Impact Assessment, Background document for the second working group on Life Cycle Impact Assessment of SETACEurope (WIA-2). Part 1 and 2. Int. J. LCA 4 (2) 66-74 and Int. J. LCA 4 (3) 167-174

15. ModesteKameniNematchoua. Sigrid Reiter. Analysis, reduction and comparison of the life cycle environmental costs related to an eco-neighborhood in Belgium. Sustainable Cities and Society (2019), https://doi.org/10.1016/j.scs.2019.101558.

16. J.Teller, A.F. Marique, V. Loiseau, F.Godard, C. Delbar, Référentiel Quartiers Durables (Guides méthodologiques), Namur, Belgique, SPW, DG04, 2014.

17. Riera Perez, M.G., \& Rey, E. (2013). A multi-criteria approach to compare urban renewal scenarios for an existing neighborhood. Case study in Lausanne (Switzerland).Build. Environ. 65, 58- 70.

18. Site web of International Energy Statistics,https://www.eia.gov/beta/international/ data/browser/\#/?

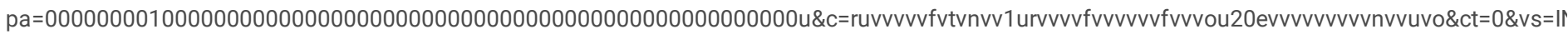
2-BLR-QBTU.A\&ord $=C R \& v o=0 \& v=H \& e n d=2016$

19. JanRemund, Stefan Müller, Stefan Kunz, Barbara Huguenin-Landl, Christian Studer, René Cattin. Global Meteorological Database Version 7 Software and Data for Engineers, Planers and Education.METEOTESTFabrikstrasse 14 CH-3012 Bern Switzerland.(2017)1-17.www.meteotest.com, www.meteonorm.com

20. Peuportier, B., Popovici, E., \&Troccmé, M. (2006). Analyse du cycle de vie à l'échelle du quartier, bilan et perspectives du projet ADEQUA. Build. Environ.2013.03.017.

21. ecoinvent LCl database. https://simapro. com/databases/ ecoinvent/?gclid= CjwKCA jwsdfZBRAkEiwAh2z65sg-fOIOpNksILo.Web site consultedin 2017.

22. Goedkoop M., Spriensma R. The Eco indicator 99: A damage oriented method for life cycle impact assessment. 2000, p142

23. GuinéeJ.B.,(final editor), Gorréeb M. Heijungs R. Huppes G. Lyfe cycle assessment;an operational guide to the ISI Standard, 2001, P704.

24. Byron A. Ellis. Life Cycle Cost.2007.p2-8.See Barringer's free LCC Excel file at http://www.barringer1.com/lcc.xls.

25. Colombert, M., De Chastenet, C., Diab, Y., Gobin, C., Herfray, G., Jarrin, T., \&Trocmé, M. (2011). Analyse de cycle de vie à l'échelle du quartier: un outil d'aide à la décision? Le cas de la ZAC Claude Bernard à Paris (France). Environnement Urbain/UrbanEnvironment, 5, c1-c21. 
26. Salomon, T., Mikolasek, R., \&Peuportier, B. (2005). Outil de simulation thermique du bâtiment, COMFIE ,from Journée SFT-IBPSA, Outils de simulation thermo-aéraulique du bâtiment, La Rochelle, $8 \mathrm{p}$.

27. Leo De Nocker, VITO - WimDebacker, VITO. Annex: Monetisation of the MMG method (update 2017).(2018)1-65.

28. 28. Debacker, W., Allacker, K., De Troyer, F., Janssen, A., Delem, L., Peeters, K., De Nocker, L., Spirinckx, C., Van Dessel, J. (2012), MilieugerelateerdeMateriaalprestatie van Gebouwelementen, finaal rapport (Environmental Material Performance of Building Elements Final Report). Public Waste Agency of Flanders (OVAM), available through http://www.ovam.be/sites/default/files/FILE1349102121400ovor121001_MMG_eindrapport.pdf .

29. De Nocker L., S. Broekx, I. Liekens (2011), Economischewaardering van verbetering ecologischetoestandoppervlaktewater op basis van onderzoeksresultatenuitAquamoney, Vito intern rapport 2011/RMA/R/248, 2011, 58 p.

30. 30. MatthewS.Tokarik,RussellC.Richman. Life cycle cost optimization of passive energy efficiency improvements in a Toronto house. EnergyandBuildings118(2016)160-169.

31. M.S. Tokarik, R.C. Richman, Life cycle cost optimization of passive energy efficiency improvements in a Toronto house, Energy Build. 118 (2016) 160169.

32. Bouwman AF, Van VUUREN DP. Global assessment of acidification and eutrophication of natural ecosystems. RIVM report 402001012.( 1999$) 2-64$.

33. 33. Xiao Yang,XiangWu,Hu-lin Hao, and Zhen-li He. Mechanisms and assessment of water eutrophication.J Zhejiang Univ Sci B. 2008 Mar; 9(3): 197-209

34. ModesteKameniNematchoua, Jacques Teller, Sigrid Reiter.Statistical life cycle assessment of residential buildings in a temperate climate of northern part of Europe. Journal of Cleaner Production 229 (2019) 621-631.

35. Tae Hyoung Kim and Chang U Chae.Environmental Impact Analysis of Acidification and Eutrophication Due to Emissions from the Production of Concrete.Sustainability2016, 8, 578; doi:10.3390/su8060578

36. 36. ModesteKameniNematchoua, Sigrid Reiter. Life cycle assessment of an eco-neighborhood: influence of a sustainable urban mobility and photovoltaic panels. International Conference on Innovation Applied Energy 14-15 March,2019, St Cross College, University of Oxford, UK

37. 37. Laffoley, D., Baxter, J.M., Turley, C., et Lagos, N.A., (éditeurs). 2017. Introduction à l'acidification de l'océan :ce que c'est, ce que nous savons et ce qui peut arriver. UICN, Gland, Suisse, 30 pp.

38. 38. Modeste Kameni Nematchoua, José A. Orosa, Sigrid Reiter. Life cycle assessment of two sustainable and old neighbourhoods affected by climate change in one city in Belgium: A review. Environmental Impact Assessment Review 78 (2019) 106282.

\section{Figures}

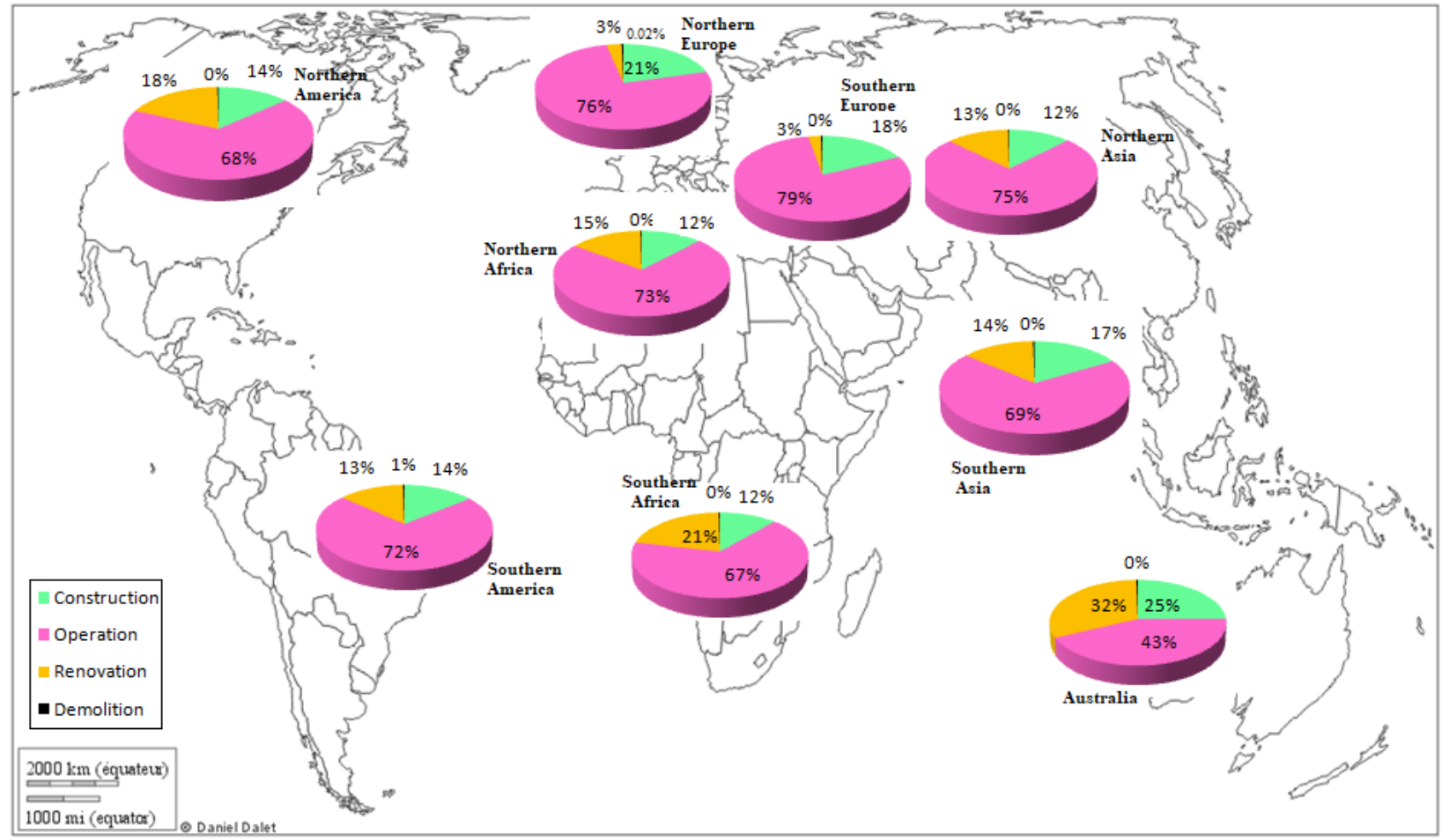

\section{Figure 1}

Distribution of acidification potential frequency of different phase of the sustainable neighborhood in several world regions (figure has been drawn with QGIS.org, 2021. QGIS Geographic Information System. QGIS Association. http://www.qgis.org ). 


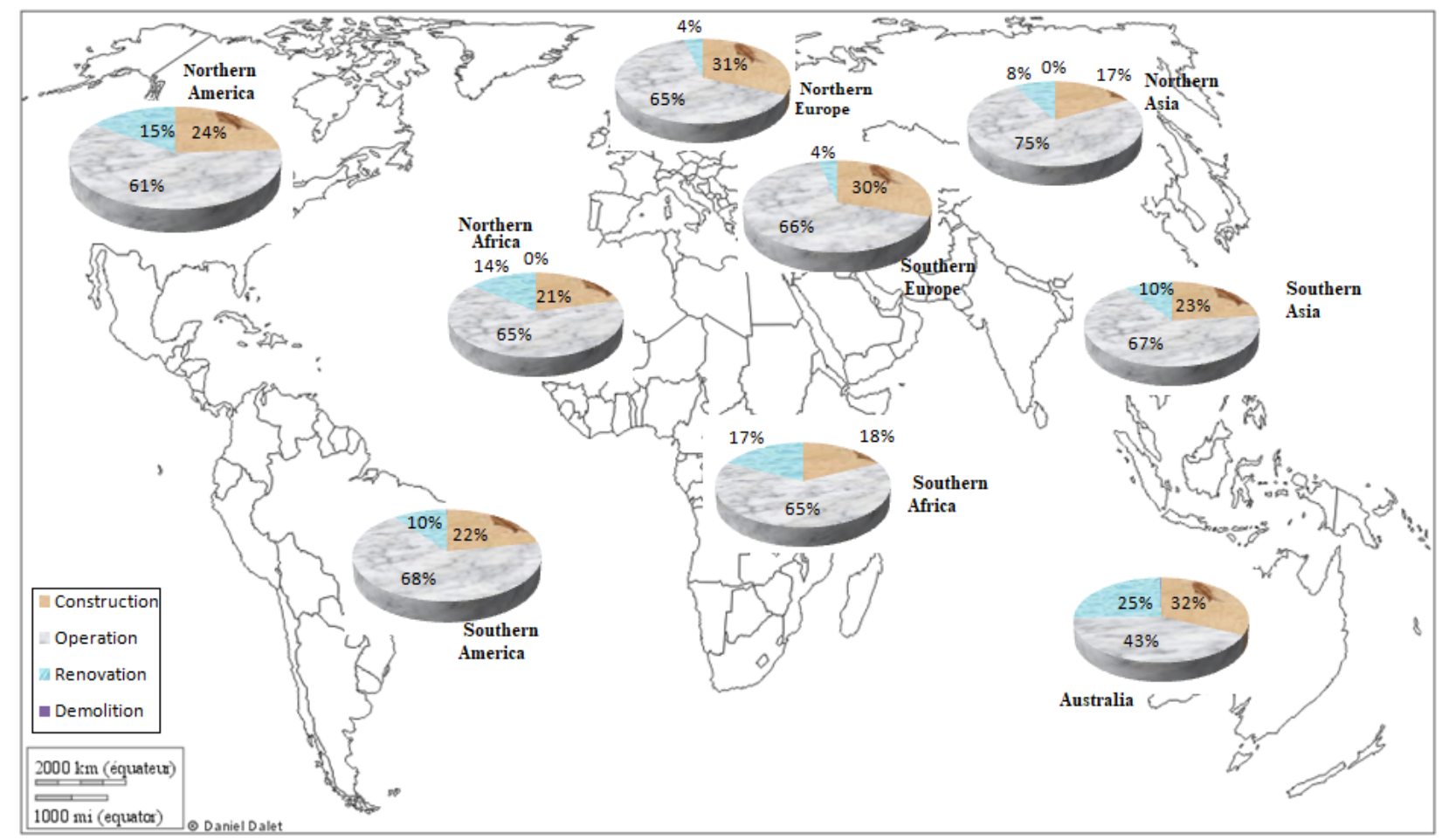

\section{Figure 2}

Distribution of eutrophication potential of different phase of the sustainable neighborhood in several world regions (figure drawn with QGIS.org, 2021. QGIS Geographic Information System. QGIS Association. http://www.qgis.org ).

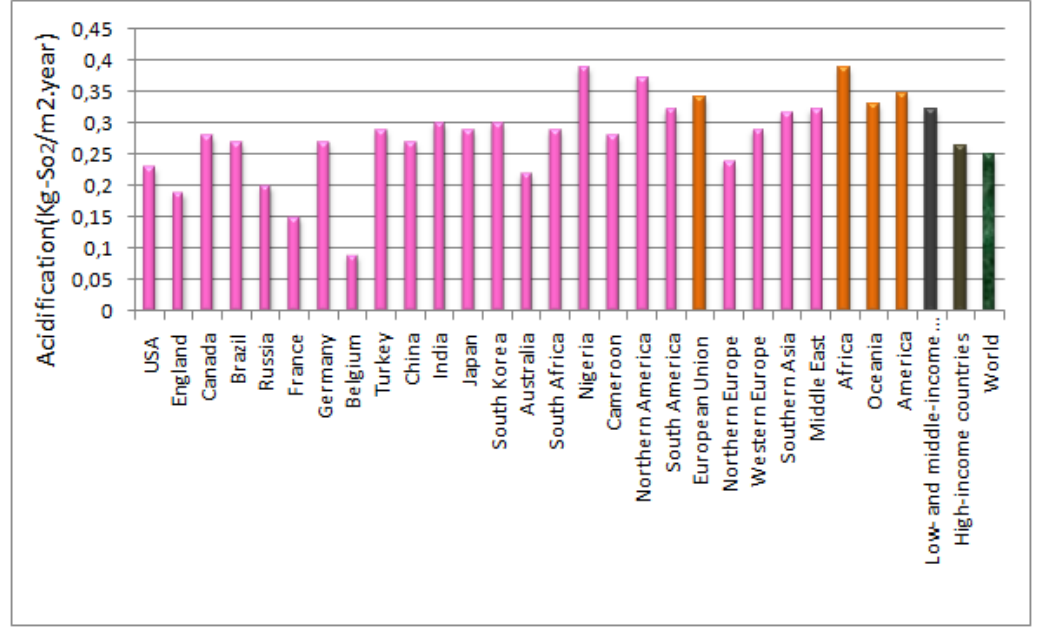

\section{Figure 3}

Assessment of acidification quantity per square meter coming from a sustainable neighbourhood distributed in some countries, regions, and continents in the world (figure drawn with R software https://www.programmingr.com/examples/neat-tricks/r-citation/). 


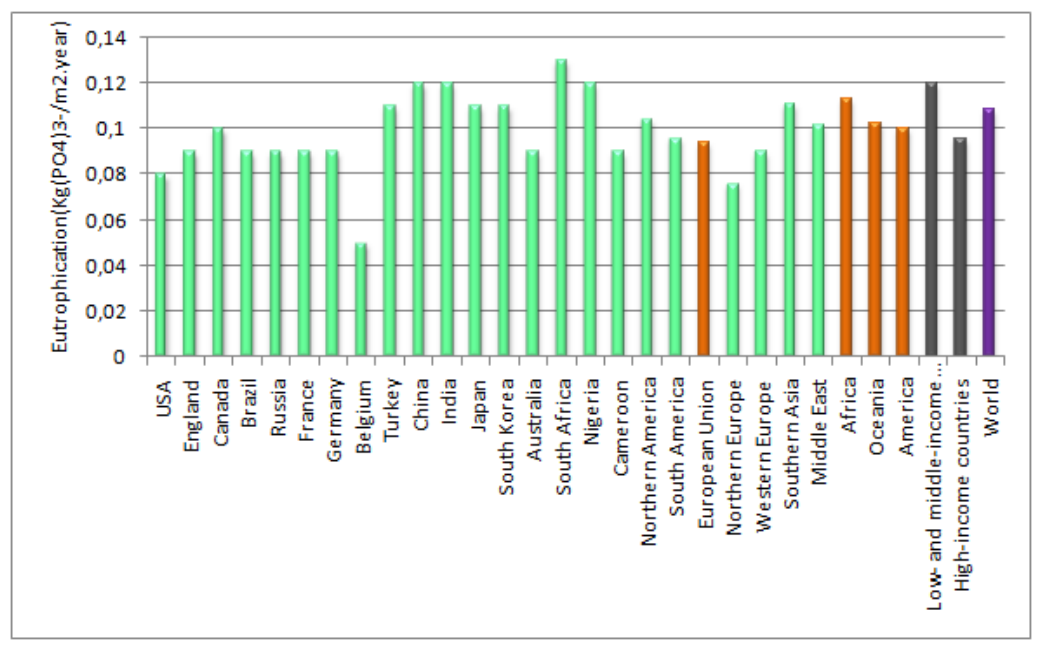

\section{Figure 4}

Assessment of eutrophication quantity per square meter coming from a sustainable neighbourhood distributed in some countries, regions, and continents in the world (figure created with R software -https://www.programmingr.com/examples/neat-tricks/r-citation/).

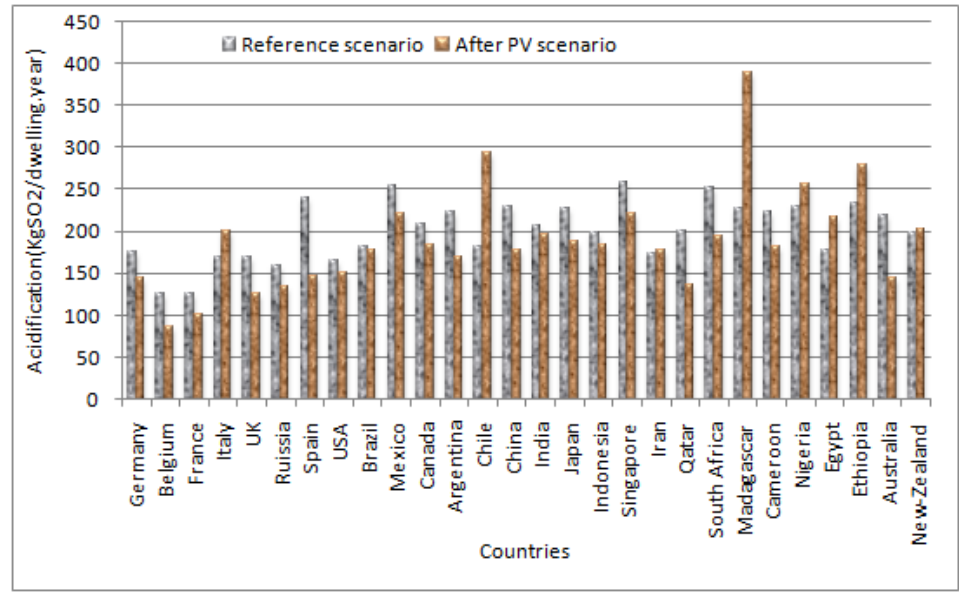

\section{Figure 5}

Comparative diagram of the Acidification impact of the "Initial" and "Photovoltaic" Scenarios (Functional Unit: dwelling) (figure created with R softwarehttps://www.programmingr.com/examples/neat-tricks/r-citation/).

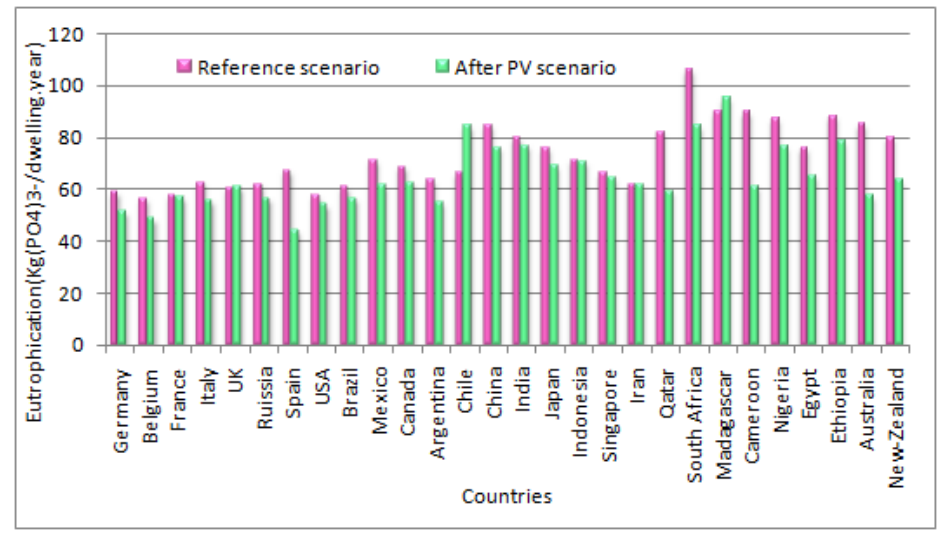

\section{Figure 6}

Comparative diagram of the Eutrophication impact of the "Initial" and "Photovoltaic" Scenarios (Functional Unit: dwelling), (figure created with R softwarehttps://www.programmingr.com/examples/neat-tricks/r-citation/). 


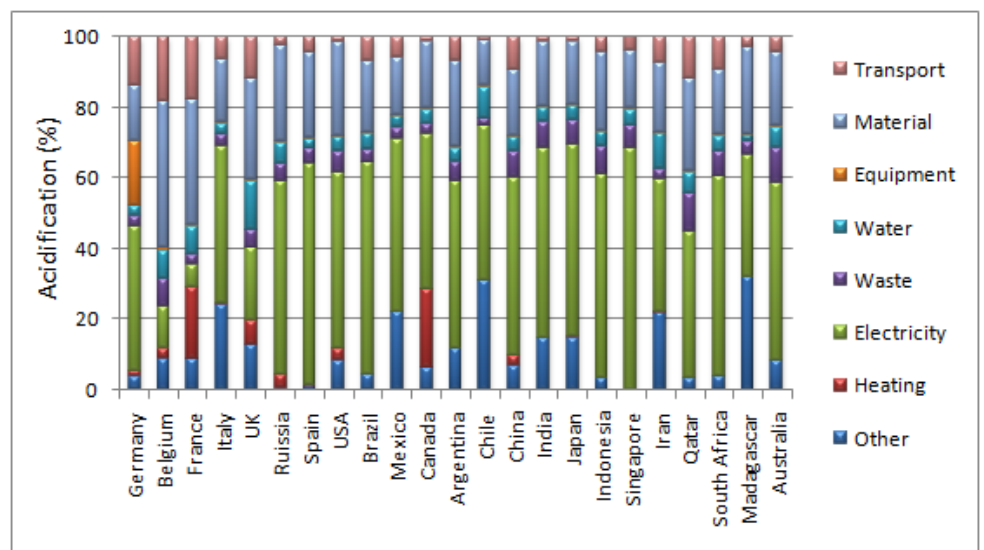

Figure 7

Frequency (\%) of the different environmental components in the generation of the acidification, for some countries located in the five continents of the world (figure created with IBM SPSS-Statistical software).

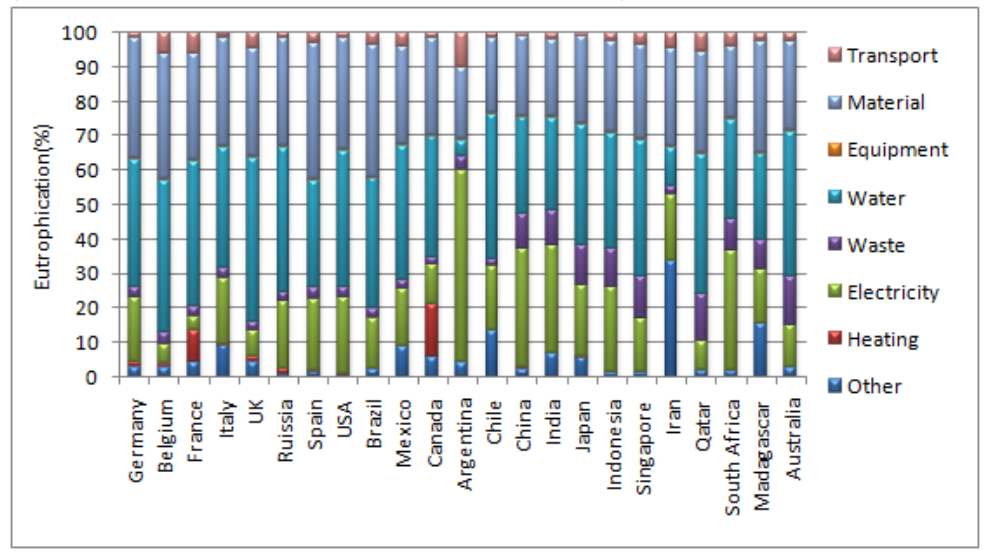

\section{Figure 8}

Frequency (\%) of the different environmental components in the generation of the eutrophication, for some countries located in the five continents of the world figure created with IBM SPSS-Statistical software). 